\title{
Experimental Design Analysis on the Efficiency of Grain Yields of Cowpea Varieties in the three Senatorial Zones of Osun State, Nigeria
}

\author{
Ojo Thompson $\mathrm{O}^{1}$, Ogunleye Timothy $\mathrm{A}^{2^{*}}$, Olawuwo Simeon ${ }^{3}$ and \\ Adeleke Mariam $\mathrm{O}^{4}$ \\ $2^{*}$ (Department of Budget, Planning, Research \& Statistics, Ejigbo Local Government, State of Osun, Nigeria) \\ ${ }_{1,3}$ (Department of Statistics, Federal Polytechnic Ede, Private Mail Bag 231, State of Osun, Nigeria) \\ ${ }^{4}$ (Department of Statistics, University of Ilorin, Private Mail Bag 1515, Ilorin, Kwara State, Nigeria) \\ $2 *$ Corresponding Author's Contacts- Mobile: +23468998580,Electronic mail: thompsondx@ gmail.com
}

\begin{abstract}
This paper, which is based on the experiment conducted by Ministry of Agriculture and Food Security, State Government of Osun within 2012 planting season, investigates the best variety of cowpea in each of the three senatorial zones of Osun State with a view to recommending variety of cowpea that will produce optimum yields. Four common varieties of cowpea: IAR341, IT8D994, IAR1696 and LOCAL were considered in the experiment with one farmland each selected from individual zone as block. Randomized Complete Block Design (RCBD) with the assumption of random effect model was used in collecting the data sets on grain yields of cowpea varieties. Observations were taken from Iwo, Ila and Esa-Oke Farmlands representing Osun West, Osun Central and Osun East Senatorial Zones. Bartlett's statistic was used to test for the validity of homogeneity of error variances for the data sets obtained from each zone. The test revealed that the assumption of equality of error variances was not violated. Shapiro-Wilk test was employed to check for validity of normality assumption on the data sets in each zone and, it was confirmed that departure from normality was not established. While the two assumptions were valid, ANOVA was conducted on the data sets and it was concluded that the mean grain yields of cowpea varieties are significantly different in the three zones. Duncan Multiple Range Test (DMRT) was employed to perform pair-wise comparisons of the varieties of cowpea. Box Plots were drawn for cowpeas varieties in each zone with a view to recommending the best variety for planting. It was established that LOCAL will perform best and produce optimum grain yield while IAR1696 will give the least yields in Osun West Senatorial Zone. We also discovered that IAR1696 produced maximum grain yields in both Osun East and Central Senatorial Zones for which LOCAL and IT8D994 produced the least yields in the two zones respectively.
\end{abstract}

Keywords: ANOVA, Bartlett's statistic, Box Plots, DMRT, RCBD, Shapiro-Wilk test, Varieties of Cowpea.

\section{Introduction}

Cowpea or bean, as it is popularly called, is rich in protein and carbonhydrate. The genus of cowpea is a relatively large pan-tropical genus with the majority of its species being found in Africa [1]. The name 'cow pea' probably originated from the fact that the plant was an important source to hay cow in the Southern United States as well as other part of the world [2]. Cowpeas are grown extensively, and can be eaten alone or with maize, rice, fish and garri - an African meal made from cassava. Its botanical name is (Vigna unguiculata) [2]. Cowpea is sometimes grown as cover crops because it is leguminous plant and is valuable for improving soil fertility. It plays an important part in crop rotation and can be dug into soil green. Cowpea grows best on fertile, loamy soil with rainfall of 36-60 inches during the growing month [2]. It also grows best in dry areas of the northern part of Nigeria. Seeds are sown as a single crop in July to August in the northern area of Nigeria, while in September; seeds are sown in the southern part of Nigeria [3]. They are inter-planted with yams, maize, sorghum and other crops.

However, the seeds are planted in holes (4cm deep). Germination occurs in 4-5 days after planting. Cowpeas mature 2-4 months after planting and they are harvested when the pod turns yellow [3]. The yields of cowpea are low because of serious pest attacks. Otherwise, yields of about $224-672 \mathrm{~kg} / \mathrm{ha}$ are obtained if cowpeas are grown as sole crops and about $168-448 \mathrm{~kg} / \mathrm{ha}$ are obtained when it is inter-planted with other crops [4]. Finally, the grains should be treated with insecticides to destroy pests before being stored in narrow necked pots. The common pests of cowpea are Bee weevils, Root knot, eelworm, beetles, etc. There are four major varieties of cowpeas (beans) under consideration - IAR341, IT8D994, IAR1696 and LOCAL respectively.

\subsection{Objectives of the Study}

- To recommend the best variety of cowpea for planting in each of the three Senatorial Zones of Osun State. 
- To determine which of the four selected varieties of cowpea will give least grain yields after germination.

- To investigate whether plots of land has a significant effect on the grain yields of cowpea varieties in each of the three Senatorial Zones of Osun State.

\subsection{Basic Principles of Experimental Design}

There are three major principles associated with Design and Analysis of Experiment. These are itemized as follows:

(a) Replication: This is defined as the repetition of the same treatments on different experimental plots. It is inversely proportional to experimental error. It makes it possible to access the experimental error (mean square error) that is required for testing the presence of treatment effects.

(b) Randomization: This is the use of random process to assign experimental units to treatments. It is employed to help averaging out the effect of many extraneous variables that are present in the experiment. Randomization removes systematic bias and ensures that each treatment has equal chance of being allocated to any particular experimental plots thereby enhancing the fulfillments of the assumptions of independent error system and the validity of the ANOVA test.

(c) Blocking: This is the process by which experimental material is partitioned into sets or blocks of homogeneous units. This is intended to ensure reduction in experimental error by isolating all possible sources of variations. Blocking is a design technique used to improve precision with which comparisons among the factors of interest are made. Often, blocking is used to reduce or eliminate the variability transmitted from nuisance factors, that is, factors that may influence the experimental response but in which we are not directly interested [5].

\subsection{Review of Some Literatures}

Cowpea (Vigna unguiculata) is a food and animal feed crop grown in the semi-arid tropics covering Africa, Asia, Europe, United States and Central and South America. It originated and was domesticated in Southern Africa and was later moved to East and West Africa and Asia. The grains contain 25\% protein, and several vitamins and minerals [2]. The plant tolerates drought, performs well in a wide variety of soils, and being a legume replenishes low fertility soils when the roots are left to decay. It is grown mainly by small-scale farmers in developing regions where it is often cultivated with other crops as it tolerates shade. It also grows and covers the ground quickly, preventing erosion [3]. Cowpea's high protein content, its adaptability to different types of soil and intercropping systems, its resistance to drought, and its ability to improve soil fertility and prevent erosion makes it an important economic crop in many developing regions [4]. The sale of the stems and leaves as animal feed during the dry season also provides a vital income for farmers.

It has been established that more than 5.4 million tons of dried cowpeas are produced worldwide, with Africa producing nearly 5.2 million. Nigeria, the largest producer and consumer, accounts for $61 \%$ of production in Africa and 58\% worldwide. More than 11 million hectares are harvested worldwide, $97 \%$ of which is in Africa. Nigeria harvests 4.5 million hectares annually [6]. The crop can be harvested in three stages: while the pods are young and green, mature and green, and dry respectively. All parts of the cowpea crop are used as all are rich in nutrients and fibre. In Africa, humans consume the young leaves, immature pods, immature seeds, and the mature dried seeds. The stems, leaves, and vines serve as animal feed and are often stored for use during the dry season. Fifty-two percent of Africa's production is used for food, $13 \%$ as animal feed, $10 \%$ for seeds, $9 \%$ for other uses, and $16 \%$ is wasted [6].

While holding lips on the production and consumption, cowpea plant is attacked by pests during every stage of its life cycle. Aphids extract juice from its leaves and stems while the crop is still a seedling and also spread the cowpea mosaic virus. Flower thrips feast on it during flowering, pod borers attack its pods during pod growth, and bruchid weevils attack the post-harvested seeds. The plants are also attacked by diseases caused by fungi, bacteria and viruses. Parasitic weeds Striga and Alectra choke the plants growth at all stages and nematodes prevent the roots from absorbing nutrients and water from the soil. Most cowpea crops are rain fed and although it is drought tolerant, cowpea farmers in the dry savanna areas of sub-Saharan Africa obtain low yields, estimated at about $350 \mathrm{~kg}$ per hectare [6].

Cowpea is a very good source of vegetable protein to both humans and animals in the world. Cowpea is regarded as one of the most valuable sources of protein as it is so nutritious that the latest dietary guidelines recommend that we triple our current intake from one to three cups per week. Cowpeas are comparable to meat when it comes to calories; adding cowpeas to your diet helps cut calories without feeling deprived [7]. Research revealed that cowpeas are digested slowly, keeping human body satisfied longer. Cowpeas are low in sugar, which prevents insulin in the bloodstream from spiking and causing hunger. When you substitute cowpeas for meat in your diet, you get the added bonus of a decrease in saturated fat [8]. It has been established that cowpeas have something else that meat lacks. There is a compound found only in plants called phytochemicals, these produce high antioxidants, a class of phytochemical that incapacitates cell-damaging free radicals in the body. 
Cowpeas are mostly planted by North Eastern and North Western parts of Nigeria. Available records show that these zones in Nigeria have greater percentage in the annual production of cowpeas.

\section{Methodology}

The Analysis of Variance (ANOVA) model employed in collecting the data sets was two-way classification type with and without interaction (Randomized Complete Block Design). Cowpea varieties and plots of land are the two experimental factors in the model while the three senatorial zones serve as blocks.

\subsection{Bartlett's Statistic for Testing Homogeneity Assumption}

Several statistical tests are available for testing equality of population variances but one of the popular test procedures for detecting homogeneity of population variances is the use of Bartlett's Test. The null hypothesis is such that all variances are the same for the factor being studied. Other tests may include Levene's test, Hartley's test, Box Transformation, etc. It should be noted that each of these other tests has special condition(s) for application. Therefore, values of Bartlett's statistic can be computed using the following formulae:

$$
\begin{aligned}
& K^{2}=\frac{1}{C}\left[d f_{T} \log _{e} M S E-\sum_{i=1}^{k} d f_{i} \log _{e} S_{i}^{2}\right] \sim X_{k-1 ; \alpha}^{2}, \text { where: } \\
& M S E=\frac{1}{d f_{T}}\left[\sum_{i=1}^{k} d f_{i} S_{i}^{2}\right] \text { and } C=1+\frac{1}{3(k-1)}\left\{\sum_{i=1}^{k} \frac{1}{d f_{i}}-\frac{1}{d f_{T}}\right\}
\end{aligned}
$$

Decision Rule: Reject $H_{0}$ if $K^{2}$ is greater than chi-squared calculated. Otherwise, do not reject $H_{0}$.

\subsection{Shapiro-Wilk W Test for Normality Assumption}

Before Analysis of Variance can be conducted on any data set, such data must satisfy the assumption that it comes from normal distribution. There are so many procedures for detecting departure from normality assumption. I decided to apply Shapiro-Wilk test because of its ability to sustain in parametric situations. Shapiro-Wilk statistical test could also be used to test for departure from exponential distribution. The test statistic is stated as follows:

$$
W=\frac{n}{n-1}\left\{\frac{\left[\bar{x}-x_{(1)}\right]^{2}}{\sum_{i=1}^{n}\left[x_{(i)}-\bar{x}\right]^{2}}\right\} \text {, where } x_{(1)} \leq x_{(2)} \leq \ldots \leq x_{(n)} \text { are the ordered sample }
$$

values.

The use of R-statistical package will be employed to ease the calculations and probability value will be compared with the value of the type I error for decision with a view to making reasonable conclusion. If the probability value is less than the value of the type I error, then it is reasonable to reject the null hypothesis of the presence of normality in the data sets.

\subsection{Randomized Complete Block Design: Analysis of Variance}

A Randomized Complete Block Design (RCBD) is a statistical technique which stands to minimize the experimental error removing the variability between block and the experimental units. The essence of this design is that experimental materials are divided into groups each of which constitutes a single trial or replication of all stages of the experiment. Thus, the objective is that it keeps the experimental error within each group as small as possible. Each treatment will have the same number of replicates and two systematic sources of variation are attached [9]. Truthfully, Randomized Complete Block Design is a term that originated from agricultural research in which several levels of treatment variable are all applied to each several levels of land. Despite its agricultural origin, it is widely used in many types of studies apart from agriculture such as regression, econometrics, and so on.

However, it is obvious that $\boldsymbol{Z}$ and $\boldsymbol{t}$ tests are restricted to the comparison of at most two means. Many occasions, researchers are faced with problems involving the comparison of more than two means. When more than two groups are involved, test for mean differences will lead to the use of analysis of variance. The test of difference between several population means is of common interest in research studies. Thus, the Analysis of Variance, or ANOVA by its acronym, is a method of testing the null hypothesis that several group means are equal in the population, by comparing the sample variance estimated from the group means to that estimated within the groups. The analysis of variance models with and without interaction as used in this study are stated as follows: $y_{i j}=\mu+\alpha_{j}+\beta_{i}+(\alpha \beta)_{i j}+\ell_{i j}$ and $y_{i j}=\mu+\alpha_{j}+\beta_{i}+\ell_{i j}$. The use of R-statistical 
package will be adopted to obtain all relevant estimates of the model when ANOVA tables are presented in the analysis.

\subsection{Post-Hoc Analysis and Use of Duncan Multiple Range Test}

When the null hypothesis is rejected in the conduct of analysis of variance, then it is obvious that not all treatment means are equal. If the statement of the alternative hypothesis is considered, at least in one pair of means, one mean is different from another. The rejection of the null hypothesis indicates that going further in the analysis to identify the mean(s) that is/are different from others is required. Once it has been discovered that differences exist among the means, post-hoc range tests and pair-wise comparisons can be used to determine which means differ. There are several ways to perform Post-Hoc Analysis where some assumed equal variance at each level while some do not. Examples of those that assumed equal variance at each level are Tukey test (Honestly Significant Difference test), Gabriel's test, Scheffe's test, Duncan Multiple Range test, Least Significant Difference test, Bonferroni, Sidak, Hochberg's GT $^{2}$, Dunnett, etc while examples of those that do not assumed equal variances are Tamhane's $\mathrm{T}^{2}$, Games-Howell, Dunnett C., etc. Among all, only Duncan Multiple Range Test is used to compare pairs of cowpea varieties because of its widely application and report of its good performance in detecting true differences resulting into a situation where experimentwise error rate is not included in its applications [5]. The procedures are outlined as follows:

Step I: Obtain the means of each varieties of cowpea and re-arrange the means in ascending order of magnitude; Step II: Obtain the following test statistic.

$$
R_{p}=D_{p, d f e ; \alpha} \sqrt{\frac{M S E}{\bar{r}}}
$$

Step III: Compare the result(s) of the test statistic with $\left|\bar{y}_{m}-\bar{y}_{n}\right|$. If $\left|\bar{y}_{m}-\bar{y}_{n}\right|$ is greater than $R_{p}$, we then reject the null hypothesis of equality of a pair of treatment means under consideration.

\subsection{Discussion on Box Plots}

Box plots are excellent tools for conveying location and variational information on data sets, particularly for detecting and illustrating location and variation changes between different groups of data. During its application, response variables are plotted on vertical axis while factors of interest are plotted on horizontal axis. Means or medians as well as lower and upper quartiles are parameters required to put Box plot in place thereby assumed that it is an effective tool for summarizing large quartiles of information. Summarily, Box plot is a very useful way to display data in which minimum, maximum, lower and upper quartiles including the median are obtained in a rectangular box aligned either horizontally or vertically. In this study, R-statistical package was used to obtain all the Box plots in order to ease the computations.

\subsection{Test of Homogeneity of Error Variances on the Data Sets \\ III. Analysis Of Data}

One of the basic assumptions for results of analysis of variance to hold in an experimental data set is for error variances to be the same or homogenous. Unlike non-parametric statistics, certain assumptions must be met before conducting analysis of variance on any data set. As a result of these strong conditions attached to the analysis of variance, Bartlett had developed a test statistic to verify the validity of homogenous error variances. The results of the test performed on the four cowpea varieties from each zone are presented in the following table: when R-statistical package was used.

TABLE I: Table of Bartlett's Test for Testing Equality of Error Variances

$\begin{array}{lll}\text { Zones } & \text { Bartlett's statistic Conclusion }\end{array}$

\begin{tabular}{c|ccl}
\hline Iwo Farmland & $K^{2}=2.961$ & 7.81 & Homogeneity assumption holds \\
Ila Farmland & $K^{2}=0.775$ & 7.81 & Homogeneity assumption holds \\
Esa-Oke Farmland & $K^{2}=5.475$ & 7.81 & Homogeneity assumption holds \\
\hline
\end{tabular}

From the Table I above, it is crystal clear that equality of error variances is upheld in all the three zones of the state where data on grain yields of cowpea varieties were collected [bartlett.test(analysis)] [10].

\subsection{Test for Normality Assumption on the Data Sets}

Another significant criterion for model adequacy checking is the use of Shapiro-Wilk test to detect whether or not the data sets come from normal distribution. The procedures involved have been extensively discussed in the previous heading as the case may be. From R-statistical package, the following table is 
generated with a view to presenting estimates of Shapiro-Wilk W Test on the data sets from the three zones [shapiro.test(residual)] [10].

TABLE II: Table of Shapiro-Wilk W Test for Normality Assumption

Zones Shapiro-Wilk Statistic $P_{\text {Value }}$

Conclusion

\begin{tabular}{c|ccl}
\hline Iwo Farmland & $\mathrm{W}=0.9222$ & 0.1832 & No departure from normality assumption \\
Ila Farmland & $\mathrm{W}=0.9516$ & 0.5162 & No departure from normality assumption \\
Esa-Oke Farmland & $\mathrm{W}=0.8332$ & 0.0784 & No departure from normality assumption
\end{tabular}

From the Table II above, Shapiro-Wilk statistic confirmed that when the data sets on the grain yields of cowpea varieties from the three zones under consideration were inspected for normality assumption, the assumption was upheld.

\subsection{Analysis of Variance on the Grain Yields of Cowpea Varieties in each of the three Senatorial Zones}

In this subheading, I wish to present the results of the analysis of variance on the grain yields of cowpea varieties in each of the three Senatorial Zones comprising Osun West, Osun Central and Osun East in Osun State, Nigeria.

TABLE III: Result of Analysis of Variance for grain yields of Cowpea Varieties from Osun West (Iwo Farmland)

\begin{tabular}{|c|ccc|c|} 
Source of Variation & Sum of Squares & $\begin{array}{c}\text { Mean } \\
\text { Square }\end{array}$ & $F_{\text {ratio }}$ & $F_{3,9 ; 0.05}$ \\
\hline Varieties of Cowpea & 0.7619 & 0.2539 & 4.659 & 3.86 \\
Plot of Land & 0.1719 & 0.0573 & 1.051 & 3.89 \\
Residual & 0.4906 & 0.0545 & - & - \\
\hline
\end{tabular}

TABLE IV: Result of Analysis of Variance for grain yields of Cowpea Varieties from Osun Central (Ila Farmland)

\begin{tabular}{c|ccc|c} 
Source of Variation & Sum of Squares & $\begin{array}{c}\text { Mean } \\
\text { Square }\end{array}$ & $F_{\text {ratio }}$ & $F_{3,9 ; 0.05}$ \\
\hline Varieties of Cowpea & 0.6373 & 0.2124 & 22.626 & 3.86 \\
Plot of Land & 0.2104 & 0.0701 & 7.469 & 3.89 \\
Residual & 0.0845 & 0.0094 & - & -
\end{tabular}

TABLE V: Result of Analysis of Variance for grain yields of Cowpea Varieties from Osun East (Esa-Oke Farmland)

\begin{tabular}{c|ccc|c|} 
Source of Variation & Sum of Squares & $\begin{array}{c}\text { Mean } \\
\text { Square }\end{array}$ & $F_{\text {ratio }}$ & $F_{3,9 ; 0.05}$ \\
\hline Varieties of Cowpea & 0.2420 & 0.0807 & 7.809 & 3.86 \\
Plot of Land & 0.1171 & 0.0390 & 3.778 & 3.89 \\
Residual & 0.0930 & 0.0103 & - & - \\
\hline
\end{tabular}

From Tables III, IV and V, it is reasonable to conclude, after rejecting the null hypotheses, that cowpea varieties are not the same in the three zones under consideration while in both Osun West and East Senatorial Zones, effects of the plot of land are not significant at 0.05 level whereas only effect of the plot of land in Osun Central (Ila Farmland) is significant. The implication of this is that effect of plot of land in Ila Farmland does not have any contribution to the yields of cowpea varieties under study. As a result of these analyses so far, the conduct of Post-Hoc Analyses (Multiple Comparison) using Duncan Multiple Range Test statistic to compare pairs of cowpea varieties with a view to establishing other hidden facts is needed.

\subsection{Application of Duncan Multiple Range Test Statistic for Post-Hoc Analyses}

It has been established in the previous subheading that the null hypotheses were rejected on the grain yields of cowpea varieties from the three zones; this is an indication for the conduct of Post-Hoc Analyses on the data sets. The following tables present the analyses of results on multiple comparisons of cowpea varieties. 
TABLE VI: Result of Post-Hoc for grain yields of Cowpea Varieties from Osun West (Iwo Farmland)

\begin{tabular}{|c|c|c|c|}
\hline Pairs of Cowpea & Differences & DMR Statistic & Decisions \\
\hline LOCAL Vs IAR 1696 & $\left|\bar{y}_{3 .}-\bar{y}_{4 .}\right|=0.525$ & $R_{4}=0.398$ & Pairs are significantly different \\
\hline LOCAL Vs IAR 341 & $\left|\bar{y}_{1 .}-\bar{y}_{4 .}\right|=0.50$ & $R_{3}=0.390$ & Pairs are significantly different \\
\hline LOCAL Vs IT8D 994 & $\left|\bar{y}_{2 .}-\bar{y}_{4 .}\right|=0.20$ & $R_{2}=0.374$ & Pairs are not significantly different \\
\hline IT8D 994 Vs IAR 1696 & $\left|\bar{y}_{2 .}-\bar{y}_{3 .}\right|=0.325$ & $R_{3}=0.390$ & Pairs are not significantly different \\
\hline IT8D 994 Vs IAR 341 & $\left|\bar{y}_{1 .}-\bar{y}_{2 .}\right|=0.30$ & $R_{2}=0.374$ & Pairs are not significantly different \\
\hline IAR 341 Vs IAR 1696 & $\left|\bar{y}_{1 .}-\bar{y}_{3 .}\right|=0.025$ & $R_{2}=0.374$ & Pairs are not significantly different \\
\hline
\end{tabular}

TABLE VII: Result of Post-Hoc for grain yields of Cowpea Varieties from Osun Central (Ila Farmland)

\begin{tabular}{|c|c|c|c|}
\hline Pairs of Cowpea & Differences & DMR Statistic & Decisions \\
\hline IAR 1696 Vs LOCAL & $\left|\bar{y}_{3 .}-\bar{y}_{4 .}\right|=0.518$ & $R_{4}=0.165$ & Pairs are significantly different \\
\hline IAR 1696 Vs IT8D 994 & $\left|\bar{y}_{2 .}-\bar{y}_{3 .}\right|=0.438$ & $R_{3}=0.162$ & Pairs are significantly different \\
\hline IAR 1696 Vs IAR 341 & $\left|\bar{y}_{1 .}-\bar{y}_{3 .}\right|=0.393$ & $R_{2}=0.155$ & Pairs are significantly different \\
\hline IAR 341 Vs LOCAL & $\left|\bar{y}_{1 .}-\bar{y}_{4 .}\right|=0.125$ & $R_{3}=0.162$ & Pairs are not significantly different \\
\hline IAR 341 Vs IT8D 994 & $\left|\bar{y}_{1 .}-\bar{y}_{2 .}\right|=0.045$ & $R_{2}=0.155$ & Pairs are not significantly different \\
\hline IT8D 994 Vs LOCAL & $\left|\bar{y}_{2 .}-\bar{y}_{4 .}\right|=0.08$ & $R_{2}=0.155$ & Pairs are not significantly different \\
\hline
\end{tabular}

TABLE VIII: Result of Post-Hoc for grain yields of Cowpea Varieties from Osun East (Esa-Oke Farmland)

\begin{tabular}{|c|c|c|c|}
\hline Pairs of Cowpea & Differences & DMR Statistic & Decisions \\
\hline IAR 1696 Vs IT8D 994 & $\left|\bar{y}_{2 .}-\bar{y}_{3 .}\right|=0.315$ & $R_{4}=0.173$ & Pairs are significantly different \\
\hline IAR 1696 Vs IAR 341 & $\left|\bar{y}_{1 .}-\bar{y}_{3 .}\right|=0.230$ & $R_{3}=0.170$ & Pairs are significantly different \\
\hline IAR 1696 Vs LOCAL & $\left|\bar{y}_{3 .}-\bar{y}_{4 .}\right|=0.083$ & $R_{2}=0.163$ & Pairs are not significantly different \\
\hline LOCAL Vs IT8D 994 & $\left|\bar{y}_{2 .}-\bar{y}_{4 .}\right|=0.233$ & $R_{3}=0.170$ & Pairs are significantly different \\
\hline LOCAL Vs IAR 341 & $\left|\bar{y}_{1 .}-\bar{y}_{4 .}\right|=0.148$ & $R_{2}=0.163$ & Pairs are not significantly different \\
\hline IAR 341 Vs IT8D 994 & $\left|\bar{y}_{1 .}-\bar{y}_{2 .}\right|=0.085$ & $R_{2}=0.163$ & Pairs are not significantly different \\
\hline
\end{tabular}

\subsection{Obtaining Box Plots for grain yields on Cowpea Varieties in the three Senatorial Zones}

Recent discussion on Box Plots revealed that it is an essential statistical tool that tells more about factor being studied. We shall apply R-statistical package [10] to display Box Plot of the grain yields of cowpea varieties in each of the three senatorial zones as follows: 


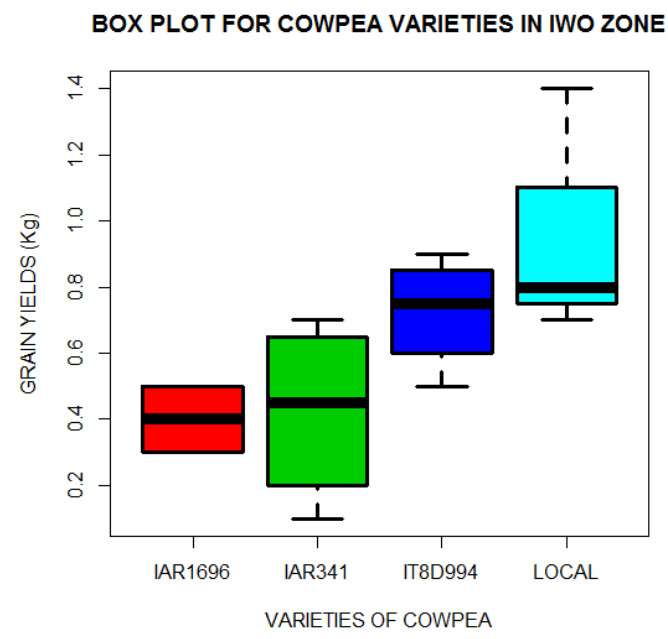

Fig. I: Box Plot for Grain Yields of Cowpea Varieties in Iwo Zone (Osun West)

BOX PLOT FOR COWPEA VARIETIES IN ILA ZONE

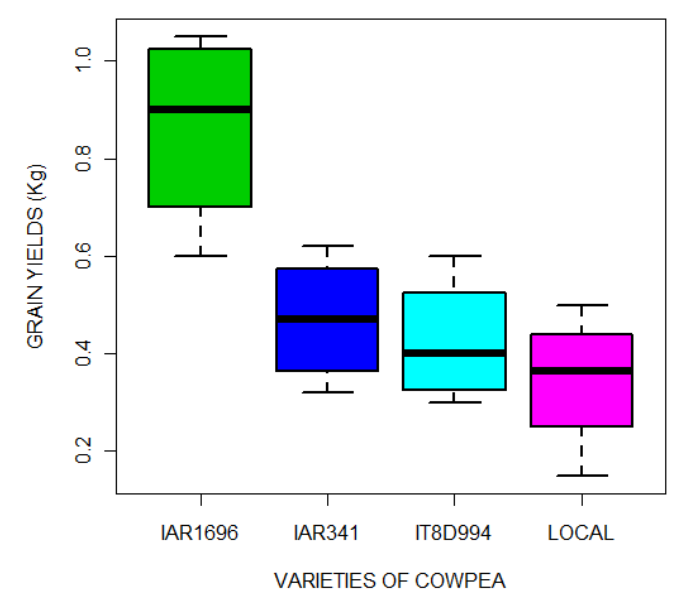

Fig. II: Box Plot for Grain Yields of Cowpea Varieties in Ila Zone (Osun Central)
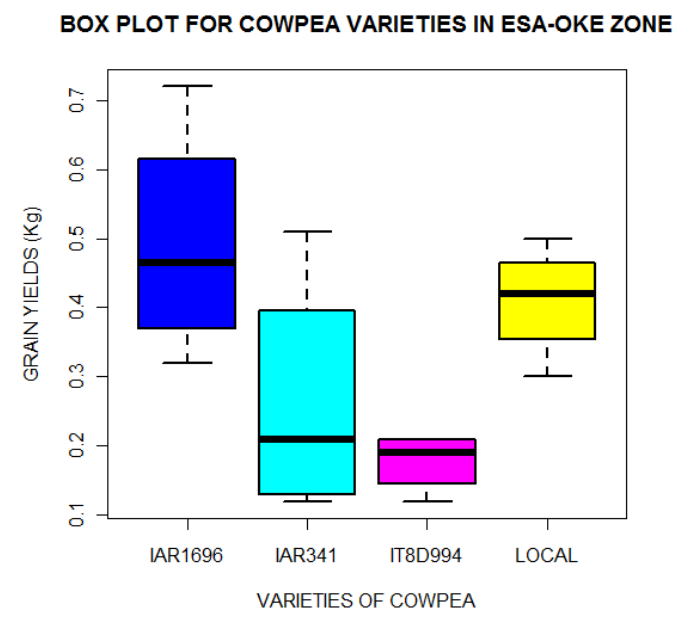

Fig. III: Box Plot for Grain Yields of Cowpea Varieties in Esa-Oke Zone (Osun East)

\subsection{Summary of Results}

\section{Summary And Conclusions}

First of all, the results obtained from the analyses of data on grain yields of cowpea varieties obtained from the three senatorial zones are discussed. The Bartlett's test carried out was to check for the equality of error variances and it was revealed that error variances are homogenous throughout the study. Shapiro-Wilk W 
statistic was applied to test for the violation of normality assumption. It was detected that the data sets were not departed from normality assumption. These lead to the computations of mean and sum of squares for the analysis of variance. From the tables of analysis of variance, it was concluded that the mean grain yields of cowpea varieties are not the same and post-hoc analysis was conducted to compare which pairs are significantly different. Box Plots were used to detect the most efficient cowpea variety.

\subsection{Conclusions}

In Osun West (Iwo Farmland), the grain yields of all varieties of cowpea (IAR341, IT8D994, IAR1696 and LOCAL) are not the same for at least two varieties. From the Box plot, it can be deduced that variety LOCAL will perform best and produce optimum yields after germination while variety IAR1696 will give the least grain yields. Therefore, it is recommended that planting of variety LOCAL should be encouraged in Iwo and its environs.

From Ila Farmland, analysis so far on the grain yields of cowpea varieties revealed that all the four selected varieties of cowpeas are significantly different in term of germination and optimality. The variety IAR1696 will perform best and produce optimum yields after germination while variety LOCAL will give the least grain yields. Therefore, it is recommended that planting of variety IAR1696 should be encouraged in Osun Central Senatorial Zone and its environs. The rest two varieties will give approximately the same results.

When the four varieties are compared in Osun East Senatorial (Esa-Oke Farmland), it has been established that the grain yields of cowpea varieties are not the same, that is, they are significantly different in terms of performance. Indication from the Box Plot showed that the variety IAR1696 will perform best and give optimum yields while the variety IT8D994 is likely to give the least yields. Therefore, the variety IAR1696 is recommended for planting in Esa-Oke and its environs with a view to realizing optimum germination. Thus, zones have effect on the yields of cowpea varieties.

\section{Acknowledgements}

Obviously, this paper would not have been possible without the encouragements and understanding of our relatives and friends. We are of the opinion to personally mention Mrs. Ogunleye-Lawal M. Oluwatoyin. Not only that name but also wish to acknowledge Mr. Ogunleye Samson Oluseyi as well as Ogunleye 'Segun Ayobami. We are also grateful to some people who have influenced us through the words of encouragement. We specially want to thank Prof. Babatunde Lateef Adeleke (Dean, Faculty of Science, University of Ilorin, Nigeria) and Pastor Afolabi Samuel Olufemi (Head of Accountancy Department, Federal Polytechnic Ede, Nigeria). Our profound gratitude are due to a set of people in persons of Comrade Oyedeji 'Femi Samson (Executive Chairman, National Union of Local Government Employees, Ifelodun Local Government Chapter, Ikirun, Nigeria), Bro. Babawale George (Administration and General Services Department in Ifelodun Local Government Area of Osun State, Nigeria), Dr Isamotu Rafiu (A Medical Practitioner in Dublin who doubles as Special Assistant to the Governor on Health Matters, State Government of Osun), Pa Solomon Adeoluwa Zaccheous (Chief Lecturer in Osun State Polytechnic, Iree, Osun State), Mr. Olaleye Michael Olugbenga (A Ph.D. Student of Accounting in Jomo Kenyatta University of Technology and Agriculture, Juja, Kenya) and Mr. Eleyele Gbadebo (Ministry of Agriculture and Food Security, State Government of Osun, Nigeria). For their behind the scenes help in academic environment, we are also grateful to Pastor R. M. Alabison (Dean, School of Pure and Applied Sciences, Federal Polytechnic Ede, Nigeria), Dr Adejumo Adebowale Olusola (Senior Lecturer in Statistics Department of the University of Ilorin, Nigeria), Dr 'Tunji Abiala (Department of Mathematical Science, Federal University of Agriculture, Abeokuta, Ogun State, Nigeria) and Dr Kolapo Ige (Senior Lecturer in Economics Department of Joseph Ayo Babalola University (JABU), Ikeji-Arakeji, Osun State). We cannot but thank Mr Adewusi Adegboyega Adelakin as well as Mr Salam Olasunkanmi (Director and Deputy Director, Department of Budget, Planning, Research and Statistics, Ejigbo Local Government Area of the State of Osun, Nigeria) for their supports and understanding at all times. We cannot forget Adegbenro Abraham Bukola of Success Business Venture, Oja-Timi, Ede, State of Osun and my educational benefactor Oyeterun Oluwafemi Samuel. Thank you all and God bless!

\section{Chapter in Book:}

\section{References}

[1] Food and Agriculture Organization (FAO). 'Agriculture Food and Nutrition for Africa-A Reserve Book for Teachers of Agriculture.' Food and Nutrition Division Chapter 4. Rome: FAO, 2012.

\section{Research Institute:}

[2] International Institute of Tropical Agriculture (IITA), Ibadan, Oyo State, Nigeria. Cowpea Crop - IITA, August, 2013 (www.iita.org.cowpea).

Theses:

[3] Boys, Kathryn. Adoption and Economic Impact Implications of Storage Technology and Improved Cowpea Varieties in the North Central Peanut Basin of Senegal. Master of Science Thesis. West Lafayette, IN: Department of Agricultural Economics, Purdue University, 2005

Research Institutes:

[4] Food and Agriculture Organization (FAO). Core Production Data for Statistical Analysis 'http://faostat.fao.org/site/340/default.aspx (accessed June 25, 2011).

Book:

[5] Douglas C. Montgomery (1997): Design and Analysis of Experiment, $5^{\text {th }}$ Edition, John Willey and Sons Inc. 


\section{Research Institutes:}

[6] International Institute of Tropical Agriculture (IITA), Ibadan, Oyo State, Nigeria. Cowpea Crop - IITA, August, 2013 (www.iita.org.cowpea).

Report:

[7] Fulton, Joan. Trip Report: June 27 - July 22, 2006, Bean/Cowpea CRSP. West Lafayette, IN: Purdue University, 2006.

Journal Paper:

[8] Singh, B. B., D.R. Mohan Raj, K.E. Dashiell, and L.E.N. Jackai, ens. Advances in Cowpea Research, Ibadan, Nigeria: International Institute of Tropical Agriculture and Japan International Research Centre for Agriculture and Sciences, 1997.

[9] Ogunleye Timothy A., Olawuwo Simeon and Olaleye M. Olugbenga. 'Economic Analysis and Modelling of Local Government Monthly Expenditure on Income in the South West Zone of Nigeria' (www.arpapress.com/Volumes/Vol. 17, Issue 2) November, 2013.

\section{Software Package:}

[10] Development Core Team (2012): R Development Core Team - 2006, R: A Language and Environment for Statistical Computing, Vienna, Austria, R Foundation for Statistical Computing. 